Reduced mitochondrial adenosine triphosphate synthesis in skeletal muscle in patients with Child-Pugh class $B$ and $C$ cirrhosis.

Quistorff, Bjørn; Bjørn Jacobsen, Esben; Hamberg, Ole; Ott, Peter

Published in:

Hepatology

Publication date:

2001

Document version

Publisher's PDF, also known as Version of record

Citation for published version (APA):

Quistorff, B., Bjørn Jacobsen, E., Hamberg, O., \& Ott, P. (2001). Reduced mitochondrial adenosine triphosphate synthesis in skeletal muscle in patients with Child-Pugh class B and C cirrhosis. Hepatology, 34(1), 7-12. 


\title{
Reduced Mitochondrial Adenosine Triphosphate Synthesis in Skeletal Muscle in Patients With Child-Pugh Class B and C Cirrhosis
}

\author{
Esben Bjørn Jacobsen, ${ }^{1}$ Ole Hamberg, ${ }^{1}$ Bjørn Quistorff, ${ }^{2}$ and Peter Ott ${ }^{1}$
}

\section{SEE EDITORIAL ON PAGE 210}

Patients with cirrhosis of the liver often complain of tiredness and a lack of strength at physical exercise. Other investigators have found that muscle strength, work capacity, and maximal oxygen consumption are reduced in cirrhosis. We hypothesized that mitochondrial maximal rate of ATP synthesis in skeletal muscle may be impaired in these patients. This was tested with ${ }^{31} \mathrm{P}$ nuclear magnetic resonance spectroscopy in anterior tibial muscle of cirrhotic patients and healthy controls at rest, during exercise, and subsequent recovery. In patients with Child-Pugh class $B$ and $C$ cirrhosis resting $\mathrm{PCr} / \mathrm{P}_{\mathrm{i}}$ ratio $(8.3 \pm 1.0 ; \mathbf{n}=7)$ was lower than in patients with Child-Pugh class A cirrhosis $(12.1 \pm 2.1 ; n=$ 7) and controls (11. $7 \pm 1.1 ; n=6 ; P=.03)$, while the resting $\mathrm{P}_{\mathrm{i}} / \gamma \mathrm{ATP}$ ratio was higher in Child-Pugh class $\mathrm{B}$ and $C$ patients $(0.43,0.30$, and 0.27 , respectively; $P=.03)$. Maximal rate of mitochondrial adenosine triphosphate (ATP) synthesis $\left(V_{\max }\right)$ as calculated from the initial rate of phosphocreatine ( $\mathrm{PCr}$ ) recovery after work was lower in ChildPugh class $B$ and $C$ cirrhosis $(0.189 \mathrm{mmol} / \mathrm{L} / \mathrm{s} \pm 0.034)$ than in both Child-Pugh class A patients $(0.402 \mathrm{mmol} / \mathrm{L} / \mathrm{s} \pm$ $0.103)$ and controls $(0.425 \mathrm{mmol} / \mathrm{L} / \mathrm{s} \pm 0.064 ; P=.01) . V_{\max }$ was significantly correlated to intracellular free $\left[\mathrm{Mg}^{2+}\right] \mathrm{ob}-$ tained from the ${ }^{31} P$ nuclear magnetic resonance (NMR) spectra $(P=.003)$. Insufficient oxygen delivery did not seem a likely cause of reduced ATP synthesis in the patients. These findings suggest either a decreased number of mitochondria in skeletal muscle of the cirrhotic patient in Child-Pugh class $B$ and $C$ or a defective mitochondrial function that could be related to low intracellular free $\left[\mathrm{Mg}^{2+}\right]$. (HePATOlogy 2001;34:7-12.)

Abbreviations: ATP, adenosine triphosphate; ADP, adenosine diphosphate; PCr, phosphocreatine; NMRS, nuclear magnetic resonance spectroscopy; $\mathrm{P}_{\mathrm{i}}$, inorganic phosphate; MVC, maximal voluntary isometric contraction; BMI, body mass index; LBM, lean body mass

From the ${ }^{1}$ Department of Hepatology A 2121, Rigshospitalet, Copenhagen University hospital, Copenhagen, Denmark; and 'Department of Medical Biochemistry and Genetics, NMR Center, The Panum Institute, University of Copenhagen, Copenhagen, Denmark.

Received September 25, 2000; accepted April 16, 2001.

Supported by grants from The NOVO Nordic Foundation and The Medical Research Foundation for Copenhagen, Faeroe Islands and Greenland (56/99) to E.B.J.

Address reprint requests to: Peter Ott, M.D., D.M.Sc., Department of Hepatology A 2121, Rigshospitalet, Copenhagen University hospital, Blegdamsvej 9, DK-2100 Copenhagen $\varnothing$, Denmark. E-mail: peterott@post3.tele.dk; fax: (45) 35452913.

Copyright $\odot 2001$ by the American Association for the Study of Liver Diseases.

0270-9139/01/3401-0003\$35.00/0

doi:10.1053/jhep.2001.25451
Patients with cirrhosis often complain of tiredness and weakness at physical exercise. In cirrhotic patients isokinetic muscle strength and work capacity have been found to be severely reduced. ${ }^{1-6}$ Fatigue and loss of muscle strength can be related to both central and peripheral phenomena. ${ }^{7-9}$ The central components are largely unknown, but probably include psychologic factors such as the mental condition and motivation of the person, as well as metabolic disturbances, e.g., hypoglycemia, hyperammoniemia, and changes in amino acid composition..$^{9}$ In cirrhosis the peripheral components possibly include decreased skeletal muscle mass, hemodynamic changes, decreased hepatic glycogenolysis, and insulin resistance. ${ }^{10}$ There may, however, also be more fundamental metabolic changes such as impaired mitochondrial function. It appears that in cirrhosis maximal oxygen consumption is decreased, ${ }^{2,3}$ which at least to some extent is a result of the decreased muscle mass in the cirrhotic patients, but which may also be the result of decreased mitochondrial oxidative capacity and/or reduced number of mitochondria in the muscle tissue. In accordance with this notion the content of adenosine triphosphate (ATP), phosphocreatine (PCr), and total $\mathrm{Mg}^{2+}$ were reported to be decreased in biopsy specimens of skeletal muscle in patients with cirrhosis. ${ }^{11-13}$ A reduced ATP/ ADP ratio was also found. ${ }^{11,12}$ In contrast to the static data available after biopsy the technique of ${ }^{31} \mathrm{P}$ nuclear magnetic resonance spectroscopy (NMRS) allows a dynamic examination of the relative concentrations of ATP, PCr, and inorganic phosphorus $\left(\mathrm{P}_{\mathrm{i}}\right)$ at rest, during, and after exercise. We used this technique to study the hypothesis that mitochondrial capacity for ATP synthesis is reduced in the skeletal muscle of the cirrhotic patient. The study indicated that this was indeed the case for patients with cirrhosis of Child-Pugh class B and $C$.

\section{PATIENTS AND METHODS}

The study included 14 patients with stable cirrhosis of the liver. Clinical data are shown in Table 1. The controls were 6 healthy individuals with similar age and sex distribution. Four patients were studied as outpatients; 10 patients were studied during their stay in our department. Patients had a self-reported abstinence from alcohol for 6 weeks or more. Inpatients were in a specialized hepatologic unit where alcohol was not allowed. Outpatients were followed on a regular 2 to 4 weekly basis and were judged abstinent from alcohol by their usual doctor. Alcohol abstinence was verified by undetectable serum-ethanol in a blood sample taken from the patients on the day of the experiment. A positive serum-ethanol excluded the patient from the experiment. Biopsy and/or ultrasonic evaluation in combination with clinical evidence of portal hypertension (prior or actual ascites and/or esophageal varices) verified cirrhosis. The etiology of cirrhosis was alcoholic in 13 patients and post-hepatitis B in one. Patients had no evidence of pulmonary or cardiac disease on routine physical examination. Child-Pugh class determinations were as fol- 
TABLE 1. Clinical Characteristics of Patients

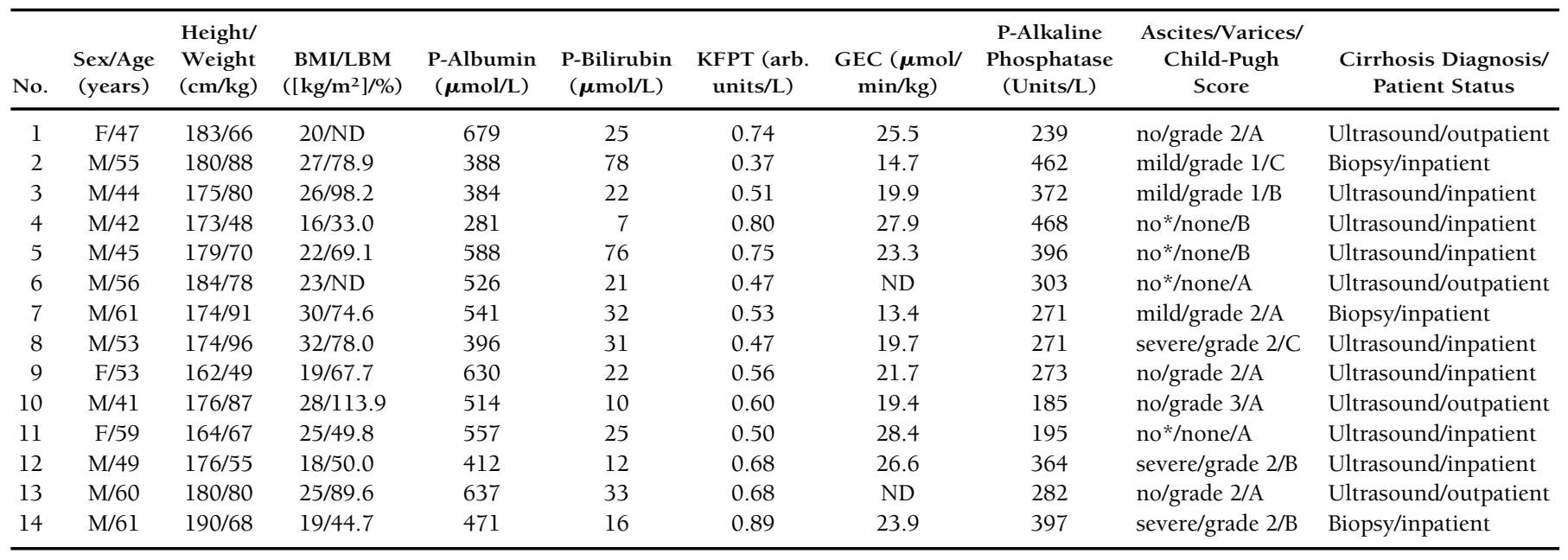

Abbreviations: LBM\%, lean body mass in percent of ideal body weight; P-Albumin reference values, female 550-800, male 600-830; P-Bilirubin reference values, 4-17; KFPT (koagulation factor II, VII and X patient/control ratio) reference value, 0.70-1.30; GEC, galactose elimination capacity (see Tygstrup ${ }^{14}$ ); P-Alkaline phosphatase reference values, 80-275 U/L; ND, not done.

*Ascites was present at the time of diagnosis, but not at the time of investigation.

lows: 7, class A; 5, class B; and 2, class C. Among Child-Pugh class A patients, 2 received propranolol (patient nos. 1 and 9), 5 spironolactone (nos. 1, 6, 7, 9, and 11), 4 furosemide (nos. 1, 7, 9, and 11), 2 losartan (nos. 10 and 13), 2 tramadolol (nos. 7 and 11), and 2 omeprazole (nos. 6 and 9). Among Child-Pugh class B and C patients, 7 received spironolactone (nos. 2, 3, 4, 5, 8, 12, and 14), 6 furosemide (nos. 2, 3, 4, 5, 12, and 14), 1 disulfiram (no. 4), and 3 omeprazole (nos. 2, 8, and 12). One Child-Pugh class A patient did not complete the exercise test, so there were 7 resting observations and 6 postexercise observations in this group. The controls were healthy persons with no history of hepatic or other disease selected among hospital staff and relatives. They included 5 men and 1 woman, ages 35 to 60 years; height 170 to $185 \mathrm{~cm}$; weight 60 to $87 \mathrm{~kg}$. Informed written consent was obtained from all participants (patients and controls). The Scientific Ethics Committee of Copenhagen and Frederiksberg Municipalities (KF 01-305/98) approved the study.

\section{Procedures}

Blood and Urine Sampling. Blood samples were obtained as part of normal hospital routine and analyzed by standard methods. A 24hour urinary creatinine excretion was measured in 12 patients on 2 successive days as an indicator of muscle mass. ${ }^{15}$

Exercise Protocol. The subjects, who were in a postprandial state, were seated with one leg (the dominant) in the magnet and maximal voluntary isometric contraction (MVC) force of dorsal flexion of the ankle was determined. Subsequently ${ }^{31} \mathrm{P}$ NMR spectra were collected during a resting period of 3 minutes followed by 3 minutes of graded rhythmic exercise at $50 \%$ of MVC with 7 seconds of contraction followed by 3 seconds rest with a total of 18 contractions. The recovery from exercise was followed for 14 minutes.

${ }^{31} P$ NMR Spectroscopy. An Otsuka Electronics Vivospec spectrometer and $80-\mathrm{cm}$ long $2.9 \mathrm{~T}$ horizontal superconducting magnet with 26-cm clear bore (Magnex Scientific) were used. A two-turn 4-cmdiameter surface coil was placed over $\mathrm{m}$. tibialis anterior approximately $10 \mathrm{~cm}$ below the patella at the point where the muscle was most prominent. The foot was fastened in an ergometer allowing measurements of the isometric force of dorsal flexion of the ankle (primarily anterior tibial muscle). Shimming on the proton signal optimized the heterogeneity of the magnetic field. The ${ }^{31} \mathrm{P}$ spectra were obtained at $49.83 \mathrm{MHz}$ by single pulse excitations ( $65 \mathrm{~ms}$ ). Data were collected in 2-k points over $205 \mathrm{~ms}$ at a 5 -second interpulse delay, and 4 modulated free induction decay signals were summed into one ${ }^{31} \mathrm{P}$ spectrum. Thus 9,9 , and $42{ }^{31} \mathrm{P}$ spectra were obtained during the 3 minutes of rest, 3 minutes of work, and 14 minutes of recovery, respectively. Data analysis involved $5 \mathrm{~Hz}$ exponential line broadening and a cubic spline baseline correction. ${ }^{16}$ Subsequently the areas of the PCr, $\mathrm{P}_{\mathrm{i}}$, and 3 ATP peaks were estimated assuming either Lorenzian or Gaussian line shape, applying a least square fitting routine. Intracellular $\mathrm{pH}$ was calculated from the difference in chemical shift between $\mathrm{P}_{\mathrm{i}}$ and PCr. ${ }^{17}$ The peak areas were corrected for the appropriate saturation factors ${ }^{18}$ and the concentrations of $\mathrm{PCr}$ and $\mathrm{P}_{\mathrm{i}}$ were calculated relative to ATP, which was assumed to be represented by $\beta$-ATP peak equal to $5.5 \mathrm{mmol}$ ATP $(\mathrm{kg} \text { wet wt })^{-1}$ in resting skeletal muscle. ${ }^{19}$ No significant changes in sugar phosphates were observed and the sum of $\mathrm{PCr}$ and $\mathrm{P}_{\mathrm{i}}$ remained constant during exercise. The PCr increase during recovery from exercise could be well approximated by a simple monoexponential function. The initial rate of $\mathrm{PCr}$ resynthesis (calculated under the assumption that the concentration of $\mathrm{PCr}+\mathrm{Cr}$ was constant during the 20-minute measurement period) was used to estimate the aerobic maximal ATP synthesis rate $\left(V_{\max }\right)$ assuming Michaelis-Menten kinetics, ${ }^{20}$ i.e., $V_{\max }=\mathrm{v}\left[\left(K_{\mathrm{m}}+\right.\right.$ ADP $\left.) / A D P\right]$, where $\mathrm{v}$ is the initial rate of PCr resynthesis, $K_{\mathrm{m}}$ is the $K_{\mathrm{m}}$ value for ADP of the respiratory chain $23 \mu \mathrm{mol} /$ $\mathrm{L},{ }^{21,22}$ and ADP is the free ADP concentration at the beginning of recovery, calculated from the creatine kinase equilibrium as explained elsewhere. ${ }^{18}$ The intracellular free $\left[\mathrm{Mg}^{2+}\right](\mathrm{mmol} / \mathrm{L})$ was calculated from the chemical shift difference of the $\alpha$-and $\beta$-peaks of ATP (ppm) after correction for $\mathrm{pH}^{.23,24}$ The assumption that ATP concentration is $5.5 \mathrm{mmol} / \mathrm{L}$ may not apply to cirrhotic patients where biopsy studies ${ }^{11}$ suggest a lower value. The possible implications will be dealt with in the Discussion.

Other Calculations. Body mass index (BMI) $\left(\mathrm{kg} / \mathrm{m}^{2}\right)$ was calculated as body weight/height ${ }^{2} .{ }^{25}$ In patients with cirrhosis and especially ascites BMI is a poor measure of nutritional status due to excess intracellular water. Therefore, we also calculated lean body mass (LBM) from 24-hour urine excretion as LBM $(\mathrm{kg})=$ Urine creatinine $\times 3.27(\mathrm{~kg} / \mathrm{mmol})+7.38(\mathrm{~kg})$. The result was then expressed as a percentage of the ideal LBM where the ideal LBM for men was $0.74 \times$ ideal body weight, and the ideal LBM for women was $0.68 \times$ ideal body weight. Ideal body weight was defined as in Metropolitan Life insurance standard tables 1983.15,26

\section{Statistics}

Results are given as mean \pm SEM unless otherwise stated. Differences were tested by Student's 2-tailed $t$ test for groups of nonpaired observations. Linear regression analysis was performed by method of 
TABLE 2. Results

\begin{tabular}{|c|c|c|c|c|c|}
\hline & $\begin{array}{c}\text { Controls } \\
\text { Mean } \pm \text { SEM }\end{array}$ & $\begin{array}{l}\text { Child-Pugh A } \\
\text { Mean } \pm \text { SEM }\end{array}$ & $\begin{array}{c}t \text { Test, } \\
\text { Unpaired A } \\
\text { vs. Controls }\end{array}$ & $\begin{array}{c}\text { Child-Pugh B and C } \\
\text { Mean } \pm \text { SEM }\end{array}$ & $\begin{array}{c}t \text { Test, } \\
\text { Unpaired B } \\
\text { and } C \text { vs. } \\
\text { Controls }\end{array}$ \\
\hline $\mathrm{PCr} / \mathrm{Pi}$ & $11.7 \pm 1.1$ & $12.1 \pm 2.1$ & NS & $8.3 \pm 1.0$ & .03 \\
\hline $\mathrm{PCr} / \gamma \mathrm{ATP}$ & $3.1 \pm 0.2$ & $3.1 \pm 2.1$ & NS & $3.3 \pm 0.4$ & NS \\
\hline $\mathrm{Pi} / \gamma \mathrm{ATP}$ & $0.27 \pm 0.03$ & $0.30 \pm 0.06$ & NS & $0.43 \pm 0.06$ & .03 \\
\hline Postexercise dynamic values & $N=6$ & $\mathrm{~N}=6$ & & $\mathrm{~N}=7$ & \\
\hline PCr recovery halftime (s) & $27.5 \pm 4.3$ & $31.7 \pm 8.6$ & NS & $55.8 \pm 7.4$ & .006 \\
\hline Maximal ATP synthesis rate $(\mathrm{mmol} / \mathrm{L} / \mathrm{s})$ & $0.425 \pm 0.064$ & $0.402 \pm 0.103$ & NS & $0.189 \pm 0.034$ & .01 \\
\hline End of exercise intracellular $\mathrm{pH}$ & $6.77 \pm 0.06$ & $6.76 \pm 0.13$ & NS & $6.90 \pm 0.03$ & .05 \\
\hline \multicolumn{6}{|l|}{ Cholestatic markers } \\
\hline P-bilirubin $(\mu \mathrm{mol} / \mathrm{L})$ & $10 \pm 1$ & $24 \pm 3$ & .005 & $35 \pm 12$ & NS \\
\hline P-alkaline phosphatase (U/L) & $159 \pm 33$ & $250 \pm 18$ & .02 & $390 \pm 27$ & .0003 \\
\hline
\end{tabular}

Abbreviation: NS, not significant.

least squares by use of a computer program (Sigmastat for Windows 2.0 Jandel Corp., Chicago, IL). $P<.05$ was considered statistically significant.

\section{RESULTS}

The main findings are shown in Table 2. Patients in ChildPugh class $\mathrm{B}$ and $\mathrm{C}$ had a significantly lower resting $\mathrm{PCr} / \mathrm{P}_{\mathrm{i}}$ ratio, longer PCr recovery halftime, and lower maximal mitochondrial ATP synthesis rate than patients in Child-Pugh class $\mathrm{A}$ and controls. Intracellular $\mathrm{pH}$ showed no differences among groups at rest. End of exercise intracellular $\mathrm{pH}$ was significantly higher in patients who were Child-Pugh class B and $C$ compared with patients who were Child-Pugh class A and controls (Table 2). There were no differences in BMI in the 3 groups (patients, 23; range 16-32; controls, 24; range 21-26). The patients did, however, show clinical evidence of malnutrition, and in 12 patients LBM was calculated. These patients had a mean LBM of $71 \%$ of expected value (range $33 \%-113 \%$ ), 4 patients were severely malnourished (33\%$50 \%$ of expected value), 5 patients were moderately malnourished (LBM $68 \%-79 \%$ of expected value), and 3 patients had a normal LBM (90\%-113\% of expected value). LBM was lower in patients who were Child-Pugh class $B$ and $C$ than patients who were Child-Pugh class A (64.6\% vs. $79.1 \%)$, but the difference was not significant. LBM calculations were significantly correlated with the ratio of $\mathrm{PCr} / \mathrm{P}_{\mathrm{i}}\left(r^{2}=.45, P=.02\right)$ but neither to the ratios of $\mathrm{P}_{\mathrm{i}} / \gamma \mathrm{ATP}$ or $\mathrm{PCr} / \gamma \mathrm{ATP}$ nor to mitochondrial ATP synthesis rate. BMI could not be correlated to any of the above-mentioned ratios or concentrations. Intracellular free $\left[\mathrm{Mg}^{2+}\right]$ was insignificantly lower in Child-Pugh class $B$ and $C$ patients than in controls $(P=.11$, Table 2$)$. There was a significant correlation between intracellular free $\left[\mathrm{Mg}^{2+}\right]$ and maximal mitochondrial ATP synthesis rate $\left(r^{2}=.40, P=\right.$ .003; Fig. 1). P-alkaline phosphatase was significantly higher in the 2 groups of patients than in controls (Table 2), but there was no correlation to intracellular free $\left[\mathrm{Mg}^{2+}\right]$ or maximal mitochondrial ATP synthesis rate.

\section{DISCUSSION}

The main result of the present study was that the maximal mitochondrial rate of ATP synthesis in skeletal muscle was lowered in patients with cirrhosis in Child-Pugh class B and C but not in Child-Pugh class A patients as compared with healthy controls. In accordance with these findings, resting values of $\mathrm{PCr} / \mathrm{P}_{\mathrm{i}}$ were lower in Child-Pugh class B and $\mathrm{C}$ patients. As possible reasons for this observation, we will consider reduced oxygen delivery, reduced intracellular free $\left[\mathrm{Mg}^{2+}\right]$, alcohol intake, medicine, malnutrition, a reduced number of mitochondria in muscle cells, and mitochondrial dysfunction caused by cholestasis.

The calculations described in the Methods section rest on certain assumptions. To the extent that these are not met in cirrhotic patients it is important to consider potential biases. The ratios $\mathrm{PCr} / \mathrm{P}_{\mathrm{i}}, \mathrm{PCr} / \gamma \mathrm{ATP}$, and $\mathrm{P}_{\mathrm{i}} / \gamma \mathrm{ATP}$ were calculated directly from the relevant peak areas. The calculations of $\mathrm{pH}$ and intracellular free $\left[\mathrm{Mg}^{2+}\right]$ rested on simple chemical principles and we see no reason why these should not apply to patients with cirrhosis. PCr recovery halftime was calculated from a monoexponential fit to the PCr versus time curve. The only assumption was that the concentration of $\mathrm{PCr}+\mathrm{Cr}$ is constant during the 20-minute measurement period, which seems very reasonable. $V_{\max }$ was calculated as $\mathrm{v}\left[\left(K_{\mathrm{m}}+\mathrm{ADP}\right) /\right.$ ADP]. To calculate $\mathrm{v}$ and ADP, the ATP concentration was assumed to be $5.5 \mathrm{mmol} / \mathrm{L}$. A biopsy study ${ }^{11}$ suggests that the concentration of ATP may be $25 \%$ lower in cirrhotic patients. If the assumed ATP concentration of $5.5 \mathrm{mmol} / \mathrm{L}$ is decreased by, e.g., 20\%, this will cause a $20 \%$ decrease of the calculated

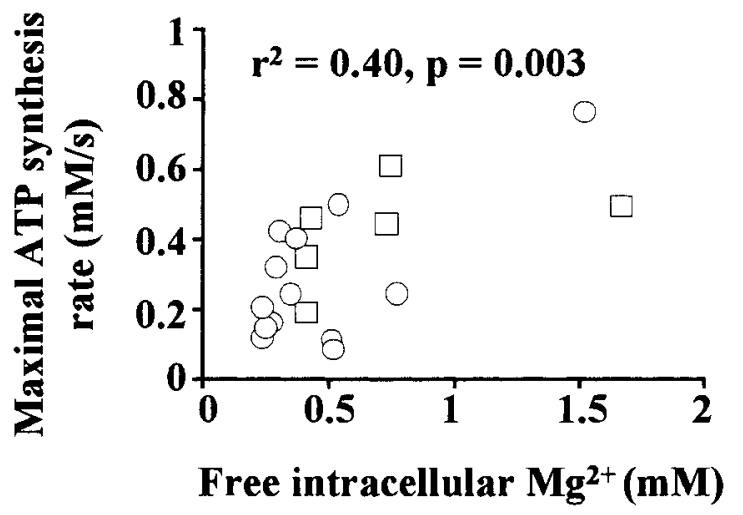

FIG. 1. The relationship between intracellular free $\mathrm{Mg}^{2+}$ and maximal mitochondrial ATP synthesis rate. The circles represent patients and the squares represent controls. 
free ADP and of the calculated rate of PCr resynthesis. A decrease of ATP concentration of, e.g., 10\%, 20\%, and 40\% translates to a decrease of $V_{\max }$ of 4,13 , and $20 \%$, respectively. Thus, if the ATP concentration was lower than $5.5 \mathrm{mmol} / \mathrm{L}$ in our cirrhotic patients, this would lead to even lower estimates of $V_{\max }$ in this group and further increase the difference between patients and controls.

Aerobic ATP production depends on the delivery of oxygen to the tissues. In other patient groups, such as patients with congestive heart failure, reduced ATP synthesis in skeletal muscle has been associated with a decreased regional blood flow. ${ }^{27,28}$ The hemodynamics of the cirrhotic patient is typically hyperkinetic with low systemic vascular resistance and high cardiac output. ${ }^{29,30}$ During exercise in normal skeletal muscle, blood flow increases up to 20-fold subsequent to an increase in cardiac output. ${ }^{31}$ At submaximal exercise in normal young individuals muscular blood flow is not thought to limit oxidative metabolism, although this may be the case in older individuals. ${ }^{32}$ Likewise in maximal exercise of a single muscle group cardiac output is not limiting oxygen uptake, rather the limitation is the capacity of the mitochondrial respiratory chain. ${ }^{33}$ Microcirculatory disturbances with dilated capillaries, reduced red blood cell transit time, and inefficient exchange of substrates between plasma and tissue have been identified in the lungs of cirrhotic patients, ${ }^{34}$ and if similar changes exist in the muscles this could lead to inefficient oxygenation during exercise. However, this would presumably lead to anerobic metabolism with a subsequent drop of muscle $\mathrm{pH}$, which was not observed. In fact intracellular acidosis was not as pronounced in the Child-Pugh class B and C patients as in Child-Pugh class A patients and controls (see Table 2). Thus, insufficient oxygen supply was not a limiting factor in our experiment. Other studies, for example the combination of near-infrared spectroscopy and NMRS could further elucidate this question. ${ }^{35}$

In muscle biopsy specimens from cirrhotic patients, decreased total Mg has been reported. ${ }^{11-13}$ Decreased intracellular free $\left[\mathrm{Mg}^{2+}\right]$ could influence mitochondrial respiration both directly and indirectly by changing mitochondrial membrane potential, ${ }^{36}$ by changing the activity of different mitochondrial enzymes, 37,38 by a reduced buffering of intramitochondrial $\mathrm{P}_{\mathrm{i}},{ }^{39}$ or by lack of inhibition of mitochondrial uncoupled respiration. ${ }^{40} \mathrm{Mg}$ deficiency has been implicated in muscle dysfunction in different clinical settings in studies using other methodologies than NMRS. ${ }^{41-44}$ In the elderly ${ }^{45,46}$ as well as in cirrhosis ${ }^{11-13}$ there seems to be a close correlation between $\mathrm{Mg}$ deficiency and low levels of energy rich phosphagen compounds in muscle biopsies. In Mg-deficient chronic alcoholic patients oral Mg supplementation increased exercise performance. ${ }^{43} \mathrm{~A}$ similar effect of oral Mg supplementation was not seen in athletes with low-normal serum magnesium values at baseline. ${ }^{42}$ In the light of these reports, it was of interest to examine if intracellular free $\left[\mathrm{Mg}^{2+}\right]$ was reduced in the patients and whether low intracellular free $\left[\mathrm{Mg}^{2+}\right]$ was related to low mitochondrial ATP synthesis rate. In contrast to the older studies, we measured the concentration of intracellular free $\mathrm{Mg}^{2+}$, which is the relevant parameter in relation to mitochondrial respiration. When all individuals, cirrhotic and controls, were pooled, intracellular free $\left[\mathrm{Mg}^{2+}\right]$ was positively correlated with maximal mitochondrial ATP synthesis rate $\left(r^{2}=.40, P=.003\right.$; Fig. 1$)$. Therefore, it is tempting to postulate that low intracellular free $\left[\mathrm{Mg}^{2+}\right]$ was the cause of the decrease of $V_{\max }$ in Child-Pugh class B and $C$ cirrhotic patients. However, a recent study suggests a rather complicated relationship between intracellular free $\left[\mathrm{Mg}^{2+}\right]$ and mitochondrial respiration, because low intracellular free $\left[\mathrm{Mg}^{2+}\right]$ may itself be secondary to defective mitochondrial respiration. ${ }^{47}$ Thus, even though intracellular free $\left[\mathrm{Mg}^{2+}\right]$ and $V_{\max }$ were correlated the possible causal relationship remains uncertain.

Alcohol abuse has been implicated in both acute and chronic morphologic and functional changes in skeletal muscle as well as magnesium depletion. ${ }^{43,48-50}$ Alcohol consumption per se has been associated with impaired muscle function, and cessation of alcohol abuse was followed by prompt objective and subjective improvement.28,50,51 Both morphologic changes of the mitochondria ${ }^{50}$ and a lower-than-normal volume fraction of mitochondria in muscles of alcoholics has been reported. ${ }^{52}$ In studies in chronic alcoholic dogs, concentrations of phosphate, $\mathrm{Mg}^{2+}$, and $\mathrm{K}^{+}$in muscle biopsy specimens were significantly reduced, and these findings were associated with disturbances in Na-K-ATPase activity. ${ }^{53}$ In human volunteers fed alcohol there was a decrease in total ATPase activity and a decreased in $\mathrm{Ca}^{2+}$ uptake via $\mathrm{Ca}^{2+}$ ATPase in the isolated membranes of the sarcoplasmic reticulum of striated muscle..$^{50}$ In patients without known hepatic disease, but with a recent alcohol abuse there was a greater PCr utilization, expressed as a greater total drop of the PCr peak measured by ${ }^{31} \mathrm{P}$ NMRS during aerobic exercise of the thenar eminence muscle. Resting $\mathrm{PCr} / \mathrm{P}_{\mathrm{i}}$ and $\mathrm{ATP} / \mathrm{PCr}$ ratios were not different from controls. Initial rates of PCr utilization or recovery were not measured and cannot be derived from the figures of that report. ${ }^{54}$ The majority of our patients had alcoholic etiology, and therefore it is important to note that all had abstained from alcohol for 6 weeks before the study and their sobriety was controlled by measuring serumethanol on the day of the experiment. In accordance, our observation of decreased $\mathrm{PCr} / \mathrm{P}_{\mathrm{i}}$ ratio consistent with a reduced capacity for oxidative phosphorylation in cirrhotic patients was different from those described after alcohol. ${ }^{54}$ Thus, recent alcohol consumption is probably not a reason for our observations. It remains to be studied whether our observations can be repeated in patients with cirrhosis of non-alcoholic origin.

Most of the patients were on some kind of medication. Because $\beta$-blockers have been reported to impair oxidative phosphorylation, ${ }^{55}$ their use was of concern in the present study. Only 2 patients, both Child-Pugh class A, received propranolol, and this seemed not to be a substantial bias because there was no difference between Child-Pugh class A patients and controls. The majority in both patient groups received diuretics. We are not aware of any toxic effect of diuretics on mitochondria, and because they were used also in the ChildPugh class A group, which was not different from controls, we suggest that they did not produce a noticeable effect in this study. In summary, we do not think that the medication of the included patients threatens our main conclusion, that ChildPugh class B and C cirrhosis was associated with impaired $V_{\text {max }}$.

Malnourishment, which is typical in cirrhotic patients, is associated with reduced muscle mass and exercise weakness. In one study of patients with alcohol-induced cirrhosis decreased muscle strength was associated with reduced muscle mass rather than with alcohol abstinence, liver function, or evidence of neuropathy. ${ }^{1}$ In malnourished patients reduced 
$\mathrm{PCr} / \mathrm{ATP}$ and $\mathrm{P}_{\mathrm{i}}$ /ATP ratios and lower PCr concentrations have been reported. $\mathrm{PCr} / \mathrm{P}_{\mathrm{i}}$ ratio was not significantly reduced, but there was a significant correlation between BMI and the ratios of PCr/ATP and $\mathrm{P}_{\mathrm{i}} / \mathrm{ATP}{ }^{56}$ These abnormalities seemed to be correlated to loss of BMI and may be caused by a relative loss of muscle creatine and phosphate in relation to ATP. ${ }^{56} \mathrm{In}$ the present study, our patients with cirrhosis were also malnourished with low LBM but normal BMI (Table 1). However, our findings were different from those in the study by Thompson et al. ${ }^{56} \mathrm{PCr} / \mathrm{P}_{\mathrm{i}}$ and $\mathrm{P}_{\mathrm{i}} / \mathrm{ATP}$ ratios were significantly lower in Child-Pugh class B and C patients compared with Child-Pugh class A patients and controls, whereas $\mathrm{PCr} / \gamma \mathrm{ATP}$ ratios were not different from controls. In accordance, neither LBM nor BMI were correlated to mitochondrial ATP synthesis rate, or to the ratios of $\mathrm{PCr} / \gamma \mathrm{ATP}$ and $\mathrm{P}_{\mathrm{i}} / \mathrm{ATP}$ as would have been expected if malnutrition was the main reason for our findings in cirrhotic patients. However, there was a correlation between LBM and $\mathrm{PCr} / \mathrm{P}_{\mathrm{i}}$ ratio $\left(r^{2}=.45, P=.02\right)$. This may indicate a relative loss of oxidative capacity with loss of muscle mass. So, while we must allow for some effect of malnutrition, this alone was insufficient to explain our data.

Because our data were calculated as ATP synthesis per unit volume, the number of mitochondria per milliliter of muscle will be a crucial factor. In bile duct-ligated rats, a secondary increase in the number of mitochondria in the liver compensate for the dysfunction of the single mitochondrion, and whole liver oxidative capacity is preserved. ${ }^{57}$ In contrast, in $\mathrm{CCl}_{4}$-treated rats with cirrhosis the number of mitochondria per liver cell is preserved and per liver reduced resulting in reduced whole liver oxidative capacity. ${ }^{58}$ To our knowledge, similar examinations of the number of mitochondria in muscle tissues of cirrhotic experimental animals have not been performed. At the same time it is well known that the concentration and size of mitochondria and activity of mitochondrial enzymes in skeletal muscle is reduced with aging and sedentary lifestyle. ${ }^{59-61}$ These changes can, to some extent, be reversed with endurance training, and even light physical activity has a positive effect on mitochondrial enzyme activity. ${ }^{61,62}$ Our patients and controls were well matched according to age but despite the fact that the controls were chosen by their sedentary lifestyle there may still be differences. To examine whether a reduced number of mitochondria per volume muscle can explain our findings, further studies including histological examination of muscle biopsies are needed. In experimental models of cirrhosis, where cirrhosis is induced with $\mathrm{CCl}_{4}$, thioacetamide, or bile duct ligation in rats, cholestasis was associated with mitochondrial dysfunctions in the liver that included specific steps of the oxidative phosphorylation. ${ }^{63}$ It has been reported that cholestasis reduced the contractility in the heart of experimental animals, ${ }^{64,65}$ and this could be due to decreased mitochondrial respiration. Several mechanisms have been proposed including inhibition of mitochondrial function by nitric oxide, ${ }^{64}$ damage by oxygen radicals due to depletion of antioxidants, and toxicity of bile acids, bilirubin, or cholesterol. ${ }^{63-66}$ It is not known whether these effects of cholestasis are also present in mitochondria from other tissues, such as striated muscle. It is an interesting possibility, because a defect oxidative phosphorylation could produce all the observations of the present study. There was, however, no correlation between P-alkaline phosphatase and maximal ATP synthesis rate even though there was a significantly higher P-alkaline phosphatase in Child-Pugh class A patients and Child-Pugh class B and C patients than in controls (Table 2).

The observation of reduced mitochondrial ATP synthesis in skeletal muscle in patients with Child-Pugh class B and C cirrhosis is of considerable clinical interest because fatigue and lack of muscle strength is such a predominant complaint in these patients and these deficits often have severe impact on social capability. This report highlights the need for further studies to explore the relative roles of, oxygen delivery in the muscular microcirculation, reduced intracellular free $\left[\mathrm{Mg}^{2+}\right]$, malnutrition and etiology of cirrhosis, the number of mitochondria, as well as more specific primary or secondary mitochondrial dysfunction that may be caused by cirrhosis.

Acknowledgment: The technical assistance of Mr. Ib Therkelsen is gratefully acknowledged.

\section{REFERENCES}

1. Andersen H, Borre M, Jakobsen J, Heden Andersen P, Vilstrup H. Decreased muscle strength in patients with alcoholic liver cirrhosis in relation to nutritional status, alcohol abstinence, liver function and neuropathy. Hepatology 1998;27:1200-1207.

2. Campillo B, Fouet P, Bonnet JC, Atlan G. Submaximal oxygen consumption in liver cirrhosis. J Hepatol 1990;10:163-67.

3. Campillo B, Chapelain C, Bonnet JC, Frisdal E, Devanlay M, Bouissou P, Fouet $\mathrm{P}$, et al. Hormonal and metabolic changes during exercise in cirrhotic patients. Metabolism 1990;39:18-24.

4. Delissio M, Goodyear LJ, Fuller S, Krawitt EL, Devlin J. Effects of treadmill exercise on fuel metabolism in hepatic cirrhosis. J App Physiol 1991; 70:210-211

5. Muller MJ, Dettmer A, Tettenhorn M, Radoch E, Fichter J, Wagner TOF, Balks HJ, et al. Metabolic, endocrine, haemodynamic and pulmonary responses to different types of exercise in individuals with normal or reduced liver function. Eur J Physiol 1996;74:246-257.

6. Gugliemi FW, Mastronuzzi T, Contento F, Scatigna F, Siciliano N, Panella C, Francavilla. Maximal oxygen consumption in chronic liver disease. In: Capocaccia L, Merli M, Riggio O, eds. Advances in Hepatic Encephalopathy and Metabolic Nitrogen Exchange. Boca Raton, FL: CRC Press Inc., 1995; 488-491.

7. Gandevia SC, Enoka RM, McGomas AJ, Stuart DG, Thomas CK. Neurobiology of muscle fatigue: advances and issues. In: Gandevia SC, ed. Advances in Experimental Medicine and Biology. New York: Plenum Press 1995;384:515-525.

8. McLester JR. Muscle contraction and fatigue. Sports Med 1997;23:287305.

9. Sahlin K, Tonkonogi M, Soderlund K. Energy supply and muscle fatigue in humans. Acta Physiol Scand 1998;162:261-613.

10. Hamberg O, Vilstrup H. Liver and skeletal muscles: muscle wasting in cirrhosis. In: Scmid R, Bianchi L, Maier KP, eds. Extrahepatic Manifestations in Liver Disease. Proceedings of Falk symposium 69. London: Kluwer Academic Publishers 1993;164-170.

11. Möller P, Bergstrom J, Furst P, Hellstrom K. Muscle biopsy studies in patients with moderate liver cirrhosis with special reference to energyrich phosphagens and electrolytes. Scand J Gastroenterol 1984;19:267272.

12. Lim P, Jacob E. Magnesium deficiency in liver cirrhosis. Q J Med 1971; 63:291-300.

13. Anderson R, Cohen M, Haller R, Elms J, Carter NW, Knochel JP. Skeletal muscle phosphorus and magnesium deficiency in alcoholic myopathy. Miner Electrolyte Metab 1980;4:106-112.

14. Tygstrup N. Determination of the hepatic elimination capacity (Lm) of galactose by single injection. Scand J Clin Lab Invest Suppl 1966;18:118125.

15. Bistrain BR, Blackburn GL, Sherman N, Scrimshaw NS. Therapeutic index of nutritional depletion in hospitalized patients. Surg Gyn Obstet 1975;141:52-56.

16. Hoch JC, Stern AS. NMR Data Processing. New York: Wiley-Liss Inc., 1996.

17. Arnold DL, Matthews PM, Radda GK. Metabolic recovery after exercise and the assessment of mitochondrial function in vivo in human skeletal muscle by means of ${ }^{31}$ P NMR. Magn Reson Med 1984;1:307-315. 
18. Quistorff B, Johansen L, Sahlin K. Absence of phosphocreatine resynthesis in human calf muscle during ischaemic recovery. Biochem J 1992;291: 681-686.

19. Bangsbo J, Johansen L, Quistorff B, Saltin B. NMR and analytic biochemical evaluation of $\mathrm{CrP}$ and Nucleotides in the human calf during muscle contraction. J Appl Physiol 1993;4:2034-2039.

20. Kushmerick MJ. Skeletal muscle: a paradigm for testing principles of bioenergetics. J Bioenerg Biomembr 1995;27:555-569.

21. Chance B, Eleff S, Bank W, Leigh Jr. JS, Warnell R. ${ }^{31}$ P NMR studies of control of mitochondrial function in phosphofructokinase-deficient human skeletal muscle. Proc Natl Acad Sci U S A 1982;79:7714-7718.

22. Chance B, Leigh Jr. JS, Clark BJ, Maris J, Kent J, Nioka S, Smith D. Control of oxidative metabolism and oxygen delivery in human skeletal muscle: a steady-state analysis of the work/energy cost transfer function. Proc Natl Acad Sci U S A 1985;82:8384-8388.

23. Ward KM, Rajan SS, Wysong M, Radulovic D, Clauw DJ. Phosphorus nuclear magnetic resonance spectroscopy: in vivo magnesium measurements in the skeletal muscle of normal subjects. Magn Reson Med 1996; $36: 475-480$

24. Clarke K, Kashiwaya Y, Todd King M, Gates D, Keon CA, Cross HR, Radda GR, et al. The beta/alfa peak height ratio of ATP. A measure of free $\mathrm{Mg}^{2+}$ using ${ }^{31} \mathrm{P}$ NMR. J Biol Chem 1996;271:21142-21150.

25. Garrow JS, Webster J. Quetelet's index $\left(\mathrm{W} / \mathrm{H}^{2}\right)$ as a measure of fatness. Int J Obes 1985;9:147-153.

26. Metropolitan Life Insurance Company. Stat Bull Metrop Life Found 1983;64:3-7.

27. Poole-Wilson PA, Buller NP, Lipkin DP. Regional blood flow, muscle strength and skeletal muscle histology in severe congestive heart failure. Am J Cardiol 1988;62:49E-52E.

28. Arnolda L, Conway M, Dolecki M, Sharif H, Rajagopalan B, Ledingham JG, Sleight $\mathrm{P}$, et al. Skeletal muscle metabolism in heart failure: a ${ }^{31} \mathrm{P}$ nuclear magnetic resonance spectroscopy study of leg muscle. Clin Sci (Colch) 1990;79:583-589.

29. Groszmann RJ. Hyperdynamic circulation of liver disease 40 years later: pathophysiology and clinical consequences. HePatology 1994;20:13591363.

30. Abelmann WH. Hyperdynamic circulation in Cirrhosis: a historical perspective. Hepatology 1994;20:1356-1358

31. Lash JM. Regulation of skeletal muscle blood flow during contractions. Proc Soc Exp Biol Med 1996;211:218-235.

32. McCully KK, Posner JD. The application of blood flow measurements to the study of aging muscle. J Gerontol A Biol Sci Med Sci 1995;50:130136.

33. Rasmussen UF, Rasmussen HN. Human skeletal muscle mitochondrial capacity. Acta Physiol Scand 2000;168:473-480.

34. Rodriguez-Roisin R, Agusti A, Roca J. The hepatopulmonary syndrome: new name, old complexities. Thorax 1992;47:897-902.

35. Hamaoka T, Mizuno M, Osada T, Ratkevius A, Nielsen AN, Nakagawa Y, Katsumura $\mathrm{T}$, et al. Changes in oxygenation and phosphocreatine during exercise and recovery in relation to fiber types and capillary supply in human skeletal muscle. In: Benaron DA, Chance B, Ferrari M, eds. Proceedings of SPIE (Progress in Biomedical Optics). 1998;3194:478-484.

36. Panov A, Scarpa A. Mg2+ control of respiration in isolated rat liver mitochondria. Biochemistry 1996;35:12849-12856.

37. Panov A, Scarpa A. Independent modulation of the activity of alphaketoglutarate dehydrogenase complex by $\mathrm{Ca} 2+$ and $\mathrm{Mg} 2+$. Biochemistry 1996;35:427-432

38. Rodriguez-Zavala JS, Moreno-Sanchez R. Modulation of oxidative phosphorylation by Mg2+ in rat heart mitochondria. J Biol Chem 1998;273: 7850-7855.

39. Jung DW, Panzeter E, Baysal K, Brierley GP. On the relationship between matrix free $\mathrm{Mg} 2+$ concentration and total $\mathrm{Mg} 2+$ in heart mitochondria. Biochim Biophys Acta 1997;1320:310-320.

40. Cadenas S, Brand MD. Effects of magnesium and nucleotides on the proton conductance of rat skeletal-muscle mitochondria. Biochem J 2000;348(Pt 1):209-213.

41. Dorup I. Effects of $\mathrm{K}^{+}, \mathrm{Mg}^{2+}$ deficiency and adrenal steroids on $\mathrm{Na}^{+} / \mathrm{K}^{+}$pump concentration in skeletal muscle. Acta Physiol Scand 1996;156: 305-311.

42. Weller E, Bachert P, Meinck HM, Friedmann B, Bartsch P, Mairbaurl H. Lack of effect of oral Mg-supplementation on $\mathrm{Mg}$ in serum, blood cells, and calf muscle. Med Sci Sports Exerc 1998;30:1584-1591.
43. Gullestad L, Dolva L $\emptyset$, Søyrand E, Manger AT, Falch D, Kjekshus J. Oral magnesium supplementation improves metabolic variables and muscle strength in alcoholics. Alcohol Clin Exp Res 1992;16:986-990.

44. Abbott LG, Rude RK. Clinical manifestations of magnesium deficiency. Miner Electrolyte Metab 1993;19:314-322.

45. Moller P, Alvestrand A, Bergstrom J, Furst P, Hellstrom K. Electrolytes and free amino acids in leg skeletal muscle of young and elderly women. Gerontology 1983;29:1-8.

46. Moller P, Bergstrom J, Furst P, Hellstrom K. Effect of aging on energyrich phosphagens in human skeletal muscles. Clin Sci (Colch) 1980;58: 553-555

47. Barbiroli B, Iotti S, Lodi R. Aspects of human bioenergetics as studied in vivo by magnetic resonance spectroscopy. Biochimie 1998;80:847-853

48. Martin F, Ward K, Slavin G, Levi J, Peters TJ. Alcoholic skeletal myopathy, a clinical and pathological study. Q J Med 1985;55:233-251.

49. Fernandez-Solá J, Sacanella E, Estruch R, Nicolás JM, Grau JM, UrbanoMarquez A. Significance of type II fiber atrophy in chronic alcoholic myopathy. J Neurol Sci 1995;130:69-76.

50. Rubin E, Katz AM, Lieber CS, Stein EP, Puszkin S. Muscle damage produced by chronic alcohol consumption. Am J Pathol 1976;83:499-516.

51. Vamvakas S, Tescner M, Bahner U, Heidland A. Alcohol abuse: potential role in electrolyte disturbances and kidney diseases. Clin Nephrol 1998; 49:205-213

52. Kiessling KH, Pilstrom L, Bylund AC, Piehl K, Saltin B. Effects of chronic ethanol abuse on structure and enzyme activities of skeletal muscle in man. Scand J Clin Lab Invest 1975;35:601-607.

53. Ferguson ER, Blachley JD, Carter NW, Knochel JP. Derangements of muscle composition, ion transport, and oxygen consumption in chronically alcoholic dogs. Am J Physiol 1984;246(5 Pt 2):F700-F709.

54. Bollaert PE, Robin-Lherbier B, Escany JM, Bauer P, Lambert H, Robert J, Larcan A. Phosphorus nuclear magnetic resonance evidence of abnormal skeletal muscle metabolism in chronic alcoholics. Neurology 1989;39: 821-824.

55. Katyare SS, Rajan RR. Altered energy coupling in rat heart mitochondria following in vivo treatment with propanolol. Biochem Pharmacol 1991; 42:617-623.

56. Thompson A, Damyanovic A, Madapallimattam A, Mikalus D, Allard J, Jeejeebhoy K. ${ }^{31} \mathrm{P}$-nuclear magnetic resonance studies of bioenergetic changes in skeletal muscle in malnourished human adults. Am J Clin Nutr 1998;67:39-43.

57. Krähenbühl S, Krähenbühl-Glauser S, Stucki J, Gehr P, Reichen J. Stereological and functional analysis of liver mitochondria from rats with secondary biliary cirrhosis: impaired mitochondrial metabolism and increased mitochondrial content per hepatocyte. Hepatology 1992;15: $1167-1172$

58. Krähenbühl L, Ledermann M, Lang C, Krähenbühl S. Relationship between hepatic mitochondrial functions in vivo and in vitro in rats with carbon tetrachloride-induced liver cirrhosis. J Hepatol 2000;33:216-223.

59. Cortopassi GA, Wong A. Mitochondria in organismal aging and degeneration. Biochim Biophys Acta 1999;1410:183-193.

60. Holloszy JO, Coyle EF. Adaptations of skeletal muscle to endurance exercise and their metabolic consequences. J Appl Physiol 1984;56:831838.

61. Wibom R, Hultman E, Johansson M, Matherei K, Constantin-Teodosiu D, Schantz PG. Adaptation of mitochondrial ATP production in human skeletal muscle to endurance training and detraining. J Appl Physiol 1992;73:2004-2010.

62. Starrit EC, Angus D, Hargreaves M. Effect of short-term training on mitochondrial ATP Production rate in human skeletal muscle. J Appl Physiol 1999;86:450-454

63. Krähenbühl S, Krähenbühl L. Mitochondrial dysfunction associated with chronic cholestasis. In: Manns MP, Boyer JL, Jansen PLM, Reichen J, eds. Cholestatic Liver Diseases. Falk symposium 102. London: Kluwer Academic Publishers 1998;107-116.

64. Van Obbergh L, Vallieres Y, Blaise G. Cardic modifications occurring in the ascitic rat with biliary cirrhosis are nitric oxide related. J Hepatol 1996;24:747-752.

65. Krähenbühl S, Stucki J, Reichen J. Mitochondrial function in carbon tetrachloride-induced cirrhosis in the rat. Biochem Pharmacol 1989;38: 1583-1588.

66. Green J, Beyar R, Sideman S, Mordechovitz D, Better OS. The "jaundiced heart": a possible explanation for postoperative shock in obstructive jaundice. Surgery 1986;100:14-20. 